\title{
Literatura
}

\section{Algunos paralelos entre los tópicos semánticos y formales de la tradición lírica hispánica y la lírica popular búlgara}

\author{
Dimitrinka G. NíkLeVA, Nadia EREMíEvA \\ Universidad de Granada \\ nikleva@ugr.es; nadia@eremia.net
}

Recibido: Junio de 2010

Aceptado: Enero de 2011

\section{Resumen}

Centramos nuestra investigación en algunos tópicos semánticos y formales en la literatura oral, presentando un estudio comparado entre la tradición lírica hispánica y la literatura oral búlgara. Profundizamos en las fórmulas y figuras de repetición en ambas literaturas, resaltando los utilizados en los temas de la belleza femenina, el amor, los rituales y las fiestas. Ofrecemos nuestra traducción de algunas muestras de poesía popular búlgara y de sus fórmulas y tópicos. Establecemos similitudes y diferencias entre ambas literaturas.

Palabras clave: Fórmulas, tópicos literarios, literatura oral búlgara, tradición lírica hispánica.

Some Parallels in Semantic and Formal Topics Between Hispanic Poetic Tradition and Bulgarian Oral Literature

\begin{abstract}
In this article we focus our attention on some semantic and formal topics in spoken literature through a comparative study between Hispanic and Bulgarian lyrical tradition. We delve into formulae and clichés in both literatures, highlighting those related to female beauty, rituals and feasts. We offer our Spanish translation of Bulgarian folk poetry, as well as their formulae or topics. We detect similarities and differences between both literatures.
\end{abstract}

Key words: Formulae, literature topics, Bulgarian oral literature, Hispanic poetic tradition.

SUMARIO: 1.Introducción; 2. Tópicos y fórmulas en la literatura oral; 3. La mañana de San Juan y el día de San Jorge; 4. Tópicos relacionados con el amor; 5. La belleza femenina; 6. Muestra variada de tópicos formales; 7. Conclusiones; 8 . Referencias bibliográficas. 


\section{Introducción}

En este artículo nos planteamos presentar un breve estudio comparado sobre los tópicos literarios en la tradición lírica hispánica y la literatura popular búlgara. Como punto de partida hay que precisar que en la literatura oral podemos incluir muchos géneros: desde las leyendas populares a las canciones, pasando por los cantos de fiesta o los cuentos infantiles. Los géneros mayores de la literatura oral serían el cuento y la lírica. En el caso de la literatura hispánica habría que añadirles el desconocido por la literatura popular búlgara romance. Junto a ellos existen los géneros menores: el refrán, los trabalenguas y las retahílas, la adivinanza, el chiste, el piropo, el pregón, el dicho popular, los apodos...

Todos ellos son manifestaciones de la tradición oral, puesto que se transmiten de generación en generación sin el soporte inmediato de textos escritos. Otra precisión relevante para nuestro estudio es señalar que "tradición" no es simple transmisión, sino que implica reelaboración, recreación por el pueblo que le imprime su espíritu particular en la infinidad de variantes de cada canto. Según Menéndez Pidal, la poesía tradicional vive en variantes. Lo tradicional implica una repetición creadora en la que se imprime el carácter personal del recreador (ARMISTEAD, 1996: 21-22).

En este artículo limitaremos el campo de estudio a la lírica popular búlgara ${ }^{1}$ y al Corpus de la antigua lírica popular hispánica junto a algunos ejemplos del Romancero. Su inclusión en nuestro trabajo obedece al criterio establecido por Margit Frenk a la hora de reunir el citado Corpus (1987: Prólogo, v):

Muy pronto comprendí que esta misma moda ["popularizante" del Renacimiento] que nos regaló los textos [en cancioneros poéticos y musicales, pliegos sueltos, obras de teatro, colecciones de refranes, etc.] los había transformado, añadiendo elementos de nuevo cuño, retocando, recreando. "No se trataba de copiar las canciones, sino de utilizarlas, de aprovecharlas como materia prima"; "al cultivarlas, las cultivaban"; "la poética popular se amalgamaba, de muy diferentes maneras, con la culta", porque "adoptar era adaptar".

En los ejemplos aducidos podremos observar algunos paralelos tanto a nivel semántico como en lo formal que podemos considerar como paneuropeos por cuanto están presentes -en variantes diversas- en toda la tradición lírica europea. Sin profundizar en todos ellos, nos centraremos en los motivos y recursos estilísticos más frecuentes dentro de los temas que representan nuestro objeto de investigación.

\section{Tópicos y fórmulas en la literatura oral}

A continuación vamos a resaltar el uso de algunos tópicos y fórmulas en la lírica popular, comparando y contrastando la tradición hispánica y la búlgara.

En cuanto a los recursos expresivos más utilizados, Menéndez Pidal señala como esenciales tres recursos estilísticos del romancero (MENÉNDEZ PIDAL, 1920:340341), que son igualmente válidos para toda la lírica popular: la repetición (sintáctica, textual o fónica), la antítesis y la enumeración.

Rasgo propio de la literatura oral es el uso del formulismo y de los tópicos. Así, por ejemplo, en la española conviene destacar el uso simbólico de algunos números con larga tradición folclórica como 2, 3 (también 30 y 300), 7 y 100. En la literatu-

\footnotetext{
${ }^{1}$ Los ejemplos aportados, que pertenecen a otras tradiciones centroeuropeas y balcánicas afines, se justifican por las proximidades socioculturales e históricas desde el punto de vista diacrónico.
} 
ra búlgara, a su vez, predominan: 3, 9, 10, 7 (АРНАУДОВ, 1977). Otros temas recurrentes y lugares comunes conocidos en la lírica hispánica son: la malmonjada, la malmaridada (malcasada), el marido celoso, las mujeres seductoras, los presos y cautivos, los religiosos... y los consiguientes adulterios, incestos, burlas, etc. Algunos de ellos tienen parangón en otras tradiciones europeas como la búlgara y otros, no.

Otro tema hispánico de gran continuidad tradicional, el de la madre como confidente y consejera: lo encontramos tanto en las jarchas, como en la lírica galaico-portuguesa y castellana y en los cantares modernos. Recordemos, por ejemplo, los villancicos:

Aquel caballero, madre, $[\ldots]$

Aquel pastorcito, madre, $[\ldots]$

Aquellas sierras, madre, [...](CEJADOR, 1987: tomo II)

En la tradición búlgara se observa también este diálogo entre madre e hija. Es habitual también la invocación de la madre (sobre todo como lamento) con el uso del vocativo en su forma hipocorística male (мале) a modo de interjección. Ejemplos de este tema encontramos en las canciones de amor:

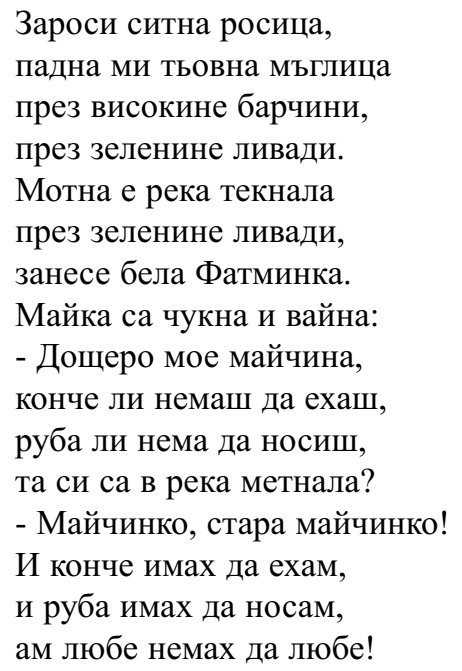

[Ver http://liternet.bg/folklor/sbornici/bnpp/liubovni/320.htm]

La tierra ajena es otro tópico de la lírica hispánica que tiene su correspondencia con un motivo en la literatura búlgara: el de la emigración (гурбет). Se suele centrar en dos motivos de marcado dramatismo: el tema de la despedida de la familia y el de bienvenida a la vuelta del extranjero. Una canción muy representativa es “Тръгнал е Тодю на гурбет да иде”. En ella se canta el enorme drama de la partida que conlleva la separación de todo lo que se estima, de tal manera que la mínima excusa -como la de tener que volver por el tabaco olvidado (,пунгяна $c$ тютюнян")-, se convierte en un obstáculo o pretexto que puede entorpecer la salida hacia lo desconocido. 
Se trata, al fin y al cabo, de un sentimiento complejo y desgarrador al que tampoco es ajena la tradición hispana:

A mi coraçón no le déis penas,

Ni desterréis por tierras agenas,

Porque no está para pasar por ellas ${ }^{2}$

A tierras ajenas,

¿quién me trajo a ellas? ${ }^{3}$

¡Ay de mí, que en tierra ajena,

me veo sin alegría!

¡cuándo me veré en la mía! $[\ldots]^{4}$

Otra fórmula hispana de larga tradición es: que de noche le mataron ${ }^{5}$. En el folclore búlgaro esta fatalidad encuentra su expresión en las recreaciones del "tiempo de división" (време разделно; разколно, разпътно). Se trata de una creencia ancestral que relaciona el tiempo del período invernal ${ }^{6}$ con la noche más oscura (sin Luna): desde la medianoche hasta el primer canto de los gallos. Es entonces cuando las fuerzas del mal dominan el mundo, "se tuercen los caminos" y es peligroso que los humanos deambulen fuera de sus hogares o alejados de la luz de la fogata que pudiera protegerlos del mal y de una confusión irreparable de su camino vital. En el mismo contexto simbólico se sitúan los tópicos de las encrucijadas y los caminos (BAJTIN, 1989:84-258).

Junto a la oscuridad de la noche, el color negro simboliza la desgracia en ambas literaturas, como podremos comprobar por los siguientes ejemplos:

Desde el día negro

que le $\operatorname{conocí}^{7}[\ldots]$

Casó María con Pedro:

casamiento negro ${ }^{8}$.

$* * *$

Че ги узе черна чума, па трьгнала по селища, по селища, по градища, съде ходи, та измори, та измори много села, много села и градища. [Ver http://liternet.bg/folklor/sbornici/minkov_1/46.htm]

\footnotetext{
2 Cartapacio de Pedro de Lemos, f. 112 (FRENK, 1987,2a:443).

3 Cancionero musical de Palacio, 362 (FRENK, 1989:177). Véase también Cancionero de Evora, Lisboa, 1875, núm. 23.

4 Cancionero de Uppsala, año 1556, núm. 22. Cantar de ausencia, del siglo XVI o más viejo (CEJADOR III:83).

5 En Lope de Vega, El caballero de Olmedo, III. (FRENK, 1989: 157). En CEJADOR III, 1987:245.

6 Véase, más adelante, lo dicho sobre la temporada comprendida entre las festividades de Sveti Dimităr y Gerg'ovden (el día de San Jorge).

7 Cancionero d'Herberay, del siglo XV (CEJADOR II, 1987: 348-349).

8 Correas, Vocab., p. 326. De malmaridada (CEJADOR I, 1987:116).
} 
Una curiosa particularidad presenta el tópico hispánico de la pérdida del color (se entiende que el blanco) que se utiliza con matices eróticos y llega a significar también la pérdida de la virginidad.

Morenica, ¿qué has tenido

qu'el color tienes perdido?

Perdida traygo la color;

todo me dizen que lo è de amor.

Viniendo de la romería

encontré a mi buen amor;

pidiéndome tres besicos,

luego perdí mi color.

dizen a mí que lo è de amor. (FRENK, 1990:126, 125)

Es muy extendido también el tópico de nacer con mala estrella. Se observa un parecido temático, léxico y expresivo en este lugar común en Flor de enamorados y Endechas ${ }^{9}$, por ejemplo. El tópico equivalente en búlgaro sería uърна орисия, пуста орисия.

Algunos de los motivos comunes a ambas tradiciones se revelarán a través de los ejemplos que estudian las constantes temáticas y expresivas relacionadas con "la mañana de San Juan" de la tradición hispánica y su festividad correspondiente del calendario búlgaro conocida como En'ov den (Еньов ден), pero también con "el día de San Jorge", más celebrado en la tradición oral búlgara. Así, por ejemplo: el de "la fuente fría" -que encontramos también en las jarchas-o el del "agua clara" y el del "agua viva"10.

Por último, se establecerán algunos ejemplos representativos a nivel formal como pueden ser las correspondencias a la extendida en la tradición búlgara fórmula tautológica “вели и говори" 11 ('habla y le dice'). Se le pueden encontrar varios paralelos en la tradición hispánica. El análogo más exacto lo encontramos en el Cancionero musical de Palacio: "y hablaba y decía" (FRENK, 87: 478)12. El Romancero, en cambio, parece mostrar preferencia por la fórmula de repetición "allí habló... bien oiréis" (MENÉNDEZ PELAYO, 1920: 369)13.

A continuación profundizaremos en algunos de estos tópicos para considerar en qué medida y bajo qué variantes se pueden encontrar en ambas tradiciones líricas populares.

\section{La mañana de San Juan y el día de San Jorge}

Especial interés por su importancia en la lírica paneuropea se merece la familiar fórmula de la lírica hispánica sobre "la mañana de San Juan" que deja entrever,

\footnotetext{
${ }_{9}$ Flor de enamorados, fol. 63 (FRENK, 1989:160) y ALVAR, Endechas, p. 115 (FRENK, 1989: 258).

10 CEJADOR II, 1987:202-203. Pero Meogo; Nunes, 415 (FRENK, 1989: 43-44). Larrea, p. 85 (FRENK, 1989:254).

11 АРНАУДОВ І, 1976: 500, 520, 531, 594.

12 Transcrito "I hablaba i dezía" (Canc. Musical. Pal, 301 (380).

13 REINOSA, Rodrigo de, Comiença un razonamiento por coplas, pliego suelto, Gallardo, t. IV, 1408. En el Cancionero de romances, Amberes, s.a, fol. 259, y de 1550, fol. 274, con variantes (M. Pelayo, Antolog.).
} 
como veremos a continuación, los ritos y celebraciones relacionados con el solsticio de verano y su carácter mágico (DÍAZ GONZÁLEZ, 1981:11)

Mañanica era, mañana

de San Juan decía en fin, [...] (CEJADOR II, 1987:207)

Mañana de San Juan, mozas;

vámonos a coger rosas. ${ }^{14}$

La mañana de San Juan

las flores florecerán.

-¿Sant Juan el Verde pasó por aquí?

-Más ha de un año que nunca le vi? (FRENK, 1990: 592 [1240B y 1241])

En la lírica popular búlgara, la mañana de San Juan se corresponde con la fiesta de En'ov den (Еньов ден, Яневден, Яновден, Летни свети Иван, Билобер, Иван Бильобер, Билбер Еньо) que marca el inicio del verano. Las creencias y costumbres populares la relacionan con la trayectoria del sol en la bóveda celeste que, llegado a su punto de madurez y esplendor, empieza a declinar hacia su muerte simbólica representada por el invierno. Durante la noche de San Juan, antes de emprender este camino, el sol madruga y se detiene para descansar, después baila una danza agitando sus rayos-espadas, da tres volteretas (прекапичва се) y destella hasta cansarse y "bañarse en el agua viva" de los ríos y del rocío de la mañana y se prepara para su despedida del mundo.

Según la creencia popular hay que esperarlo y bañarse a su salida para estar sano a lo largo del año. Es también el momento de recoger las 77 y media hierbas medicinales: las 77 que servirán para las curas habituales y la media, para las dolencias incurables. De madrugada se hacen también las coronas de hipérico, geranio, orégano y amor de hortelano (en'ovche: еньовче) у la costumbre es pasar por ellas para asegurase buena salud: se las echa a las aguas que se llevarán todo mal augurio.

Otro riual muy popular consiste en una especie de adivinación de los noviazgos y casamientos de las mozas. Se llama Nadpjavane na prastenite (Надпяване на пръстените) о En'ova bulja (Еньова буля) 15 у se lleva a cabo por las doncellas casaderas. En la víspera, todas ellas sumergen sus anillos atados a ramitas de flores en mălčana voda (мълчана вода) traída en caldero de cobre. Se ha de dejar reposar debajo de un rosal para que "vea las estrellas" durante la noche mágica y a la mañana de San Juan se viste a la más moza de ellas como novia -con velo rojo- y es ella la que va sacando las ramitas de flores, mientras las demás cantan coplas que sirven para conjurar la suerte de la propietaria del anillo y adivinar su pretendiente:

Която й мома най-доброчеста,

нейния пръстен напред да излезе!

Ой Еньо, Еньо, Еньова бульо,

сегни, извади маламян пръстен!

\footnotetext{
14 CEJADOR II, 1987: 93. FRENK, 1989: 197-198. CEJADOR III, 1987: 250-251.

15 En las regiones centrales, septentrionales y noroccidentales del país y en Sredna Gora este ritual se lleva a cabo en Nochevieja y se llama Laduvane (Ладуване), Tajlada (Тайлада) у Dajlada (Дайлада).
} 
(Честита мома)

Синьо небо, ясна звезда.

(Хубавец)

Шарен кожух черква мете.

(Учител)

[Ver: http://liternet.bg/folklor/sbornici/lirika/75.htm]

Estas tradiciones se confunden y entremezclan con rituales y creencias propias también para otra fiesta, anterior en el tiempo: Gerg'ovden, el día de San Jorge. Antiguamente se celebraba el día 23 de abril (el 6 de mayo, en la actualidad: por la reforma del calendario). Era el día que marcaba el inicio del año agrícola ${ }^{16}$ que se cerraba el día 26 de octubre, en la festividad de Sveti Dimităr (Димитровден, Митровден). La tradición popular le reconocía como el hermano mayor de San Jorge. Curiosamente, el período invernal comprendido después de su festividad se consideraba como época poco propicia para los amores que buscaban llegar a buen fin como el casamiento. Así lo describe el cantar "Шила Гъргя дълга сая... от Митровден до Гюргьовден” (МИЛАДИНОВИ ІІ, 2003: 117). Con la victoria de San Jorge sobre el dragón, en cambio, se abren las fuentes y los humedales, y se presagia el despertar de la naturaleza para su nuevo ciclo vital: es la época que favorece los amores y simboliza la esperanza y el nuevo resurgir de la vida o la resurrección en la tradición cristiana.

Estas creencias llevan a pensar en el carácter ancestral de su culto, pero hay divergencia de opiniones en cuanto a su origen. Algunos autores lo consideran como festividad tracia (ТЕОДОРОВ, 1972), otros defienden su génesis eslava (КОЛЕВА, 1981) y no faltan estudiosos que apuesten por buscar sus raíces en el pasado asiático de los antiguos búlgaros (ВЕЛЕВ, 2000).

La celebración de la festividad búlgara de San Jorge también empieza antes de la salida del sol, con un baño ritual en el rocío de la mañana en una pradera, cuando "todo está envuelto en el dulce rocío" (ТЕОДОРОВ, 1972: 11). Otra variante del ritual son los baños en lugares considerados como sagrados: en fuentes, ríos y estanques. Dicho rocío (o agua de la fuente) tiene poderes mágicos y curativos: previene de dolores de espalda y asegura la fecundidad del ganado y la prosperidad de las familias. Por ello se lo recoge y se lleva a casa, observando la exigencia de guardar silencio durante el trayecto. Así se obtiene mălčana voda (мълчана вода) - también presente en la fiesta de San Juan (Еньов ден)- que sirve como remedio curativo y para la elaboración de panes rituales (обредни хлябове). Por el camino a casa también se recogen ramas frescas de haya, geranios, lilas o, incluso, ortigas. Con ellas se hacen coronas para el ganado y se adornan los umbrales y puertas de las casas, las camas y los cuartos de los niños. Los mozos enamorados dejan engalanadas de verdor las puertas de las casas de sus escogidas, mientras que ellas lían coronas para ataviar sus tocados ${ }^{17}$. Otra costumbre muy arraigada es la de atar columpios en los

\footnotetext{
16 El mismo testimonio etnográfico han legado las pinturas murales de la Colegiata de San Isidoro de León (arte románico): en el medallón del mes de abril el personaje que representa la faena típica de la época -sin abandonar el manto todavía-, lleva una planta en cada mano: es el tiempo de la siembra.
} 
árboles vigorosos, donde los jóvenes casaderos de ambos sexos se reúnen para jugar y cantar canciones con marcado carácter erótico. Además, de los árboles se cuelgan pesas y la gente se pesa con la idea de asegurarse la salud a lo largo del año. La siguiente serie de prácticas que marcan esta gran fiesta son las relacionadas con el sacrificio de un cordero y las comidas comunales, el ordeño mágico de la luna y una serie de rituales que propician la buena cosecha y el aumento del ganado.

En los cantares tradicionales búlgaros parece tener mayor carga simbólica el día de San Jorge (Гергъовден, Гергевден, Гюрговден, Герги, Джурджовдън, Хъдърлез, Адрелес $\left.{ }^{18}\right)$, porque - a juzgar por las afirmaciones poéticas- se lo prefiere incluso antes que 'El Gran día' (Velikden): el Domingo de Resurrección.

Хубав ден Великден

още по-хубав Гергьовден ${ }^{19}$. (МАРИНОВ, 1994: 592)

Днес е свети ден, Великден, ощ по-хубав Гергьовден ${ }^{20}$. (CбНУ XIV: 7, Копривщица)

Son muchas las canciones que recogen el tema de la preponderancia del día de San Jorge -el patrón de los pastores y agricultores-, en el calendario popular festivo:

На личен ден съм родена,

на личен ден Великден,

а ощ'по на личен кръстена, на личен ден Гергьовден ${ }^{21}$. (СбНУ XXVIII: 407, Бургаско)

Llaman la atención algunos parecidos entre las dos fiestas: la de San Juan en la cultura española y el día de San Jorge y En'ov den en la tradición búlgara.

Engalanarse con flores recogidas la mañana de San Juan y adornar con ellas la cabeza o el cuerpo de la amada.

La mañana de San Juan

salen a coger guirnaldas, con sus más queridas damas

Zara, mujer del rey Chico que son Fátima y Jarifa, Celinda, Adalifa y Zaida, de fino cendal cubiertas, no con marlotas bordadas.

Sus almaizales bordados con muchas perlas sembradas, descalzos los albos pies, blancos, más que nieve blanca... (DÍAZ GONZÁLEZ, 1981:12)

\footnotetext{
17 Es bien conocida la costumbre del robo de la flor o corona del tocado de la moza en público, que es la manera de declararse oficialmente. En relación con los mismos rituales es curiosa la costumbre de la zona de Kjustendil, donde las jóvenes recogen no tanto ramas frescas, como bardana (lampaza) para adornar su ropa con la idea de que sean deseadas y no les falten pretendientes (УМЛЕНСКИ, 1950:156).

18 “Хъдърлез" у “Адрелес" son los nombres de la misma festividad celebrada también por los musulmanes búlgaros.

19 Bonito día el gran día del Señor/mejor aún el de San Jorge.

20 Hoy es día santo, el gran día del Señor/ pero mejor es el día de San Jorge.

${ }^{21}$ He nacido en un día señalado/ en el día grande del Señor/ en día señalado me han bautizado/ en el día de San Jorge, el Victor.
} 
Utilizar estas flores y ramilletes de hierbas medicinales como remedio para alguna enfermedad o dolencia, ya del cuerpo, ya del alma.

Que no cogeré yo verbena

la mañana de San Juan,

pues mis amores se van. (FRENK, 1989:135)

Cumplir con el culto telúrico y ancestral al agua y al sol a través de los baños rituales en fuentes, arroyos y mares que adquieren poderes milagrosos (BAROJA, 1985).

La mañana de San Juan

al tiempo de la alborada

bajó la Virgen María

por una fuente muy clara.

Se lavó sus pies y manos, después su bendita cara;

después de haberse lavado

dio bendiciones al agua:

-Venturosa la mujer

que aquí viniese a por agua... (DÍAZ GONZÁLEZ, 1981:13)

La iniciación al amor que es el tema central de los festejos y se recoge no solo en los cantares amorosos, sino también en las "justas" poéticas rituales que protagonizan mozos y mozas. Es significativa, en este sentido, la tradición europea que hace pensar en un origen común del "juego de lanzas" medieval y renacentista, recogida por Joaquín Díaz González en el citado artículo "La mañana de San Juan en el Romancero" que atestiguan variantes del mismo cantar:

La mañana de Sant Joan

al punto que alboreaba

gran fiesta hacen los moros

por la vega de Granada.

Revolviendo sus caballos

jugando iban las cañas, ricos pendones en ellas

labrados por sus amadas

y sus aljubas vestidas

de sedas finas y grana:

El moro que tiene amores

señales de ellos mostraba

y el que amiga no tiene

allí no escaramuzaba.

Moras los están mirando

de las torres del Alhambra

por ver que tienen amores

y quién más se aventajaba...

Observa el autor que este tipo de canciones de temas aparentemente amorosos evocan, a través de juegos y desfiles, un cierto tipo de danza popular en Europa y 
América denominada genéricamente "Morisca". En México es conocida como "moros", en España - "moros y cristianos", en Portugal - "mouriscada", en Inglaterra - "morris dance"; "moresca" - en Italia y "morevka" en la Península Balcánica:

En casi todos estos lugares, y en otros donde el nombre no se ha conservado, se observa en la fiesta -celebrada habitualmente el día de San Juan- una parodia de lucha, ocasionalmente a caballo o sobre caballos de cartón, plasmada en actos y gestos que constituyen toda la mímica de los danzantes. (DÍAZ GONZÁLEZ, 1981:12)

\section{Tópicos relacionados con el amor}

Volviendo a los tópicos de la tradición hispánica, deberíamos mencionar "el mal de amor" y "mal herido" como unos de los más difundidos (CEJADOR III, 1987: 141).

Mal ferida va la garza enamorada [...] (FRENK, 1989: 153)

En la literatura castellana el amor mata o hiere. En la búlgara, abrasa. Recordemos la palabra изгора que significa 'amado, querido' (muy usada en el folclore) y es derivada del verbo 'abrasarse, quemarse':

Върви конче, двама да вървиме,

да идеме на снощния конак, че там има до три моми хубави, първата бе хубава и не бе, а втората, конче, бе запала, а третата - изгора-запала, та изгори мене клето сърце и на конче черните дробове, и над конче ясното небе, и под конче черната земя. 22

Sin embargo, en la antigua tradición hispánica también se encuentra la comparación del amor con el fuego:

Ojos, por quien yo suspiro

abrasado en vivo fuego:

si os miro, me dejáis ciego,

y estoy ciego, si no os miro 23 .

Aquí conviene recordar que a partir del siglo XIII, la lírica popular en la Península Ibérica tuvo una clara influencia de los ideales corteses ${ }^{24}$ que introdujeron los motivos del "mal de amores" y el "morir de amor". Este es un fenómeno que no se produjo en la literatura búlgara por razones históricas.

A vos amo y a vos quiero

y a vos sirvo y serviré:

aunque siempre por vos muero,

por vuestro me nombraré 25 .

\footnotetext{
22 БУРИН и ПАНАЙОТОВА, 2005: <http://liternet.bg/folklor/sbornici/sokol/59.htm>

${ }^{23}$ CEJADOR II, 1987:93-94; CEJADOR III, 1987 : 142. "Se abrasa y muere" (CEJADOR III, 1987: 184). La idea de abrasarse la encontramos también en CORREAS, Vocab., p. 146: en CEJADOR I, 1987: 245 y 248 (Baile de Leganitos).

24 Canc. Barbieri, núm. 251, del siglo XV. Cancionero d'Herberay.

25 Cancionero d'Herberay, siglo XV (CEJADOR II, 1987: 81).
} 
Yo siempre sirviendo

tú siempre olvidando $[\ldots]^{26}$

De ahí que una consideración más atenta puede suponer el motivo del "amor que abrasa" como más antiguo y popular (en sentido de vulgar), mientras que "la muerte por amor" correspondería más al ideal promovido por la literatura cortesana. Por ello, son abundantes las variantes recogidas en el Corpus de la antigua lírica popular hispánica (1987, 2a: 276-278) que se corresponden con los versos:

¡Ay, coraçón, y cómo te quemas!

¡Ay, coraçón, con amores d'ella! (601)

¡Arded, coraçón, arded!, que no os puedo yo valer. $(602 \mathrm{~A}, \mathrm{~B}, \mathrm{C})$

Prendióme el amor, prendióme, ¡ay de mí!, prendióme y dexóme ansí. (603)

En los cantares de amor los meses preferidos son mayo y abril. Son los meses de los enamorados y del resurgir de la naturaleza y la vida. Muchos cantares repiten este verso del inicio "Por mayo era, por mayo" 27.

Que por mayo era, por mayo,

cuando los grandes calores,

cuando los enamorados

van a servir a sus amores $[\ldots]$

El amor es uno de los temas centrales de la tradición lírica popular y, como es lógico, una de sus características principales son los lugares comunes que describen el objeto del deseo. Así, este tema enlaza con el de la belleza femenina al que dedicamos el siguiente apartado.

\section{La belleza femenina}

Como en el presente artículo no nos planteamos investigar todos los tópicos semánticos y formales, además de algunos epítetos constantes, que pudieran considerarse representativos, vamos a elegir un tema que consideramos de especial interés - el de la belleza femenina en ambas literaturas- y ver el tratamiento que recibe.

De la lírica popular búlgara hemos escogido los cantares de amor para estudiar el tema que nos interesa. Los temas abarcan cualquier momento de lo vivido y lo pensado por los jóvenes. Tenemos que señalar que la creación de esta lírica se debe fundamentalmente a las mujeres, un rasgo común con la tradición peninsular ibérica. Observamos que en la caracterización de la amada la lírica hispánica muestra una predilección por los siguientes temas: el color (moreno o blanco), los ojos, el cabello, los labios, etc.

El color moreno es un tema de gran difusión, recreado por toda la poesía popular peninsular ibérica:

\footnotetext{
${ }^{26}$ Cancionero de Uppsala, año 1556, núm. 3 (CEJADOR III, 1987:125-126).

27 Cancionero general de 1511, en CEJADOR II, 1987: 217. El Cancionero Barbieri, número 69. En el Cancionero de Costantina, 2, se da con una ligera variación: "Por el mes era de mayo"; cfr. CEJADOR II, 1987:216-217. La misma se repite en una silva en Cancionero de romances, 1550 (CEJADOR II, 1987: 214-215).
} 
Yo me soy morenica, yo me soy la morena. Lo moreno bien mirado fue la culpa del pecado, que en mí nunca fue hallado ni jamás se hallará. $[\ldots]^{28}$

Es un tópico presente también en los cantares sefardíes:

Morenica a mí me llaman,

yo blanca nací;

el sol del enverano

me hizo a mí ansí.

Morenica y graciosa

y mavromatianí.

Los últimos dos versos se repiten a modo de estribillo después de cada estrofa. Observen también que mavromatianí proviene del griego y significa 'de ojos negros'.

Existen numerosas variantes que oponen el color moreno al blanco, dejando entrever las connotaciones eróticas resultantes al relacionar la blancura con la pureza y la virginidad y su pérdida - con la exposición al sol y la estancia en el campo abierto 29 :

Aunque soy morena,

blanca yo nací:

guardando el ganado

la color perdi 30 .

En todas estas variantes se puede comprobar la preferencia por la blancura e, incluso, cierto lamento por su pérdida.

Blanca tengo la cara, blanco es mi favor, que como yo puedo, tengo su color 31 .

Morenica me llaman, madre, desde el día que yo nací; al galán que me ronda la puerta rubia y blanca le parecí 32 .

Elocuente resulta también que, mientras en las cantigas de amigo la que se jacta de su color moreno es la propia voz femenina, cuando las alabanzas vienen de boca de los hombres, no queda lugar para las dudas:

\footnotetext{
${ }^{28}$ Cancionero de Uppsala, núm. 44.

${ }^{29}$ Se trata de una larga tradición que arranca con "El cantar de los cantares" (I, 5-6) en el que la amante sulamita entona su canto (Biblia Reina-Valera, rev. 1960): “morena soy, oh hijas de Jerusalén,/ pero codiciable [...] No reparéis en que soy morena,/ porque el sol me miró./Los hijos de mi madre se airaron/ contra mí;/Me pusieron a guardar las viñas; / y mi viña, que era mía, no guardé".

30 B. N. M., ms. 3915,fol. 320; en FRENK, 1989: 121,122, 123, 246. Véase también: Orozco, Cancionero, p. 320. En Lope de Vega, El gran duque de Moscovia, II. En Juan Vásquez, Recopilación, I, 8. (CEJADOR III, 1987:188). En Gonzalo Correas, Arte grande, p. 281 (CEJADOR I, 1987:222)

31 En FRENK, 1990:1108. Cancionero de Florencia, f. 233.

32 En CEJADOR I, 1987: 258. Con glosa, Rev. Hisp., t. XXIX (1913), p. 185.
} 
Blanca sois, señora mía,

más que el rayo del soli3.

En la literatura búlgara el tópico de la blancura está consagrado de manera que la belleza en sí se expresa a través del albor. La moza es "toda blanca" y esta percepción se refuerza por otros recursos estilísticos como el uso frecuente de aliteraciones: "бяло момиче", "бела Бояна", "бело се лище белее" (КОЛЕВА, 2002: I, 1.1). Esta particularidad es válida también para la lírica griega, sobre todo en el caso de las canciones de boda (АНГЕЛИЕВА, 1980: 53-54).

Como una oposición complementaria a la belleza-blancura de la doncella o la novia se presenta el doblete blanca-roja, blanca-rubí, sobre todo en referencia a la cara: "на лище бяла червена", "на лище бяла - румена" (КОЛЕВА, 2002: I, 1.1). Curioso a la hora de hacer comparaciones resulta el ejemplo que aporta Angelieva (АНГЕЛИЕВА, 1980: 52): "Kогато me взех, мое момиче, беше бяла и червена, сега си черна и бледа, срам ме е да те заведа'"34.

Este uso del color negro se asemeja bastante a lo que antes se ha dicho sobre el color moreno en la lírica hispánica. Otro ejemplo aún más reconocible es el que aporta el lamento de una mujer casada por su perdido estatus de soltería:

Куга бях малкъ къту вас,

Бяла бях къту кадъна,

червена - къту ябълка.

Като ма мама ожени,

почернях, та си погрознях

къту черната къпина 35 . (ГЕОРГИЕВА, 1986: 536)

Otros tópicos repetidísimos en la lírica popular son los ojos morenos, la piel blanca y los cabellos negros $^{36}$, pero aquí nos importa resaltar las similitudes que presentan las dos tradiciones en cuanto a la presencia del color "de oro fino" para representar el cabello:

Non son de oro mis cabellos, mas el oro fino es dellos ${ }^{37}$.

Una fórmula muy parecida nos ofrece el siguiente villancico con coplas:

No quieren ser de oro, no, señora, vuestros cabellos; antes el oro sale dellos ${ }^{38}$.

Los cabellos rubios son admirados en la lírica popular búlgara también, como indican algunos los siguientes cantares: Руса мома ще наказва лудо-младо, Русин юнак замерва със стрела руса мома, Змей Никола отвлича Руса мома. ${ }^{39}$

\footnotetext{
33 Cancionero de romances, 1550, fol. 288.

34 'Cuando te tomé eras, mi niña, blanca y roja, ahora estás negra y pálida, me da vergüenza llevarte.'

35 De moza cual vosotras, / blanca era cual novia,/ roja cual manzana,/ cuando mi madre desposóme,/negra me torné y fea, cual la zarzamora negra.

${ }^{36}$ Rev. Hisp., t. VIII (1901), p. 321. Canc. Barbieri, núm. 120 (CEJADOR III, 1987:181). Tonos castellanos, ms. Biblioteca de Medinaceli (CEJADOR I:282). Baptista Montidea, Cancionero llamado Villete de amor (CEJADOR III, 1987: 192).

37 Cancionero de Evora, Lisboa, 1875, núm. 32 (CEJADOR II, 1987: 373).

38 Canc. llamado Danza de galanes, Barcelona, 1625 (CEJADOR II, 1987: 305).

39 Con más detalles en la bibliografía final: http://liternet.bg/folklor/sbornici/sokol/59.htm http://liternet.bg/folklor/sbornici/bnt/6/638.htm http://liternet.bg/folklor/sbornici/bnpp/obredni/99.htm http://liternet.bg/publish/akaloianov/iunak/32.htm http://liternet.bg/folklor/sbornici/shapkarev_1/1135.htm http://liternet.bg/folklor/sbornici/rodna_kitka/17.htm http://liternet.bg/folklor/sbornici/rodna_kitka/17.htm
} 
El oro en los cabellos o los cabellos rubios como una señal (marca) divina que encuentra en el mundo de lo humano su más digna encarnación es compartida también por la lírica popular de la Europa central y oriental: en el folclore serbio - "pyca глава" (ВАНГЕЛОВ, 1986); en la épica rusa además de "русый” se utiliza el epíteto "белокурый" (ВЕСЕЛОВСКИЙ, 1989: 85); las canciones checas lo repiten como "svetlovlasy"; las polacas - "jasnowlosy".

Esta preferencia por las doncellas rubias no parece ser muy estable en la poesía popular balcánica donde son mayoritarios los ejemplos de cabellos negros u oscuros: “накитила тъмни куси / уд две стръни и в сридать” (ГЕОРГИЕВА, 1986: 314) или “косата й - черна ибришима" (АРНАУДОВ, ІІ-1977: 696).

Veamos también un cantar hispánico que contiene todo un retrato de la belleza femenina:

Yo me amaba señora, que en el mundo no hay su par.

Las facciones que ella tiene yo vos las quiero contar:

tal tenía la su cara como rosa en el rosal, las cejas puestas con arco, color de un fino contray, los sus ojos tenía garzos, parecen de un gavilán, la nariz afiladica como hecha de metal, los labios de la su boca como un fino coral, los dientes tiene muy blancos, menudos como la sal, parece la su garganta cuello de garza real, los pechos tenía tales que es maravilla mirar; $[\ldots]^{40}$

En las siguientes coplas podemos ver tanto lo que se apreciaba en el aspecto de la mujer como lo que se consideraba defectos. Entre los recursos expresivos utilizados predomina la anáfora (la repetición de salvo al principio de los versos).

Óyeme tu retrato, niña Isabela,

salvo que es justo, salvo que es propio, salvo que es feo, salvo que hiela.

Linda mata de pelo, peina tu mano, salvo que es corto salvo que es poco salvo que es cano.

40 Pliego suelto de la Biblioteca de Praga (CEJADOR, 1987: 98). 
Con la luz de tus ojos

a todos pierdes,

salvo ser chicos,

salvo ser bizcos,

salvo ser verdes.

La nariz en cristales

hoy se dilata,

salvo ser gorda,

salvo ser tuerta,

salvo ser chata.

Lo mejor con tu boca

nunca se mide,

salvo ser grande,

salvo ser belfa,

salvo que pide.

Que tu pie es muy hermoso

nadie lo duda,

salvo ser largo,

salvo ser tuerto,

salvo que suda 41 .

No se puede prescindir de la alusión a los ojos lindos, negros, morenos, bellos, divinos, garridos, etc. La comparación de los ojos con saetas es común en las dos tradiciones líricas (CEJADOR III, 1987:332-333).

Ojos garzos ha la niña:

¿quién se los namoraría?

Es un pareado octosílabo, glosado en el siglo XVI, pliego suelto, Coplas de cómo una dama ruega a su negro... Existe desarrollado en otras variantes. Los ojos azules fueron siempre muy estimados en España: simbolizan el cielo y el mar, también la esperanza (CEJADOR I, 1987:94). La boca se suele comparar con la miel ${ }^{42}$. Además, los labios pueden ser "labios de clavel" o "claveles finos" 43 . A veces, la descripción se detiene en los "pechos hermosos" de la mujer44. "Las teticas blancas" de una monja son el tema principal de otras poesías 45 .

En resumen, la tradición popular búlgara representa la belleza femenina por la blancura -como rasgo general-, los ojos negros -preferidos por los poetas-, los cabellos largos y brillantes como el sol y envolventes como la noche, la cara fresca como manzana, los labios que destilan miel y los pechos como flores...

Se repiten con frecuencia algunos epítetos constantes en la descripción de la belleza femenina. En ellos podemos observar la idealización y el uso común de

\footnotetext{
${ }^{41}$ Ms. 3884 Bibl. Nac. Con variantes en Floresta de varia poesia, 2a parte (CEJADOR II, 1987:99-100).

42 Correas, Vocabulario, p. 164 ${ }^{\mathrm{a}}$ (FRENK, 1989: 114).

43 Véase Poesías de diversos, ms. 3700, Bibl. Nac., en poesías de Góngora (CEJADOR III, 1987:99-100).

44 En Timoneda, Sarao, fol. 37 (FRENK, 1989:115).

45 Sánchez de Badajoz, Farsa del juego de cañas, tomo II, p. 278. Del siglo XV (FRENK, 1989:116). Otra variante en el Cancionero de Uppsala, año 1556, p. 5 (CEJADOR III, 1987: 195-196).
} 
hipérboles, que ejercen un fuerte poder de sugestión. Los ojos se suelen comparar con las estrellas brillantes (ясни звезди); las cejas, 'cinta trenzada, cordón trenzado' (плетен гайтан). La piel es blanca, los ojos son negros. Otra fórmula muy extendida es la de los 'andares menudos' (ситно ходене). La mujer guapa, además, es alta y delgada: un rasgo que no se da en el folclore español. Se le suele comparar con el álamo: тънка топола 'álamo grácil'. Mientras que en la literatura castellana, las alusiones al cuerpo son poquísimas: cuerpo garrido.

Ya hemos destacado que el cabello es un elemento esencial de la belleza femenina. La mujer es consciente de ello y lo cuida y utiliza para seducir ${ }^{46}$.

Peinarme quiero yo, madre,

porque sé

que a mis amores veré.

En otra poesía:

La novia destrenza el pelo,

y se desmaya el caballero ${ }^{47}$.

Este canto, de tantas variantes, es muy viejo. Es una canción de la fiesta de mayo o primavera, que hasta el siglo XIX se festejó con la tradicional Maya (CEJADOR II, 1987: 220).

A continuación presentamos una traducción inédita al español ${ }^{48}$ de dos poesías de la lírica popular búlgara. Son un ejemplo que sintetiza tópicos y fórmulas.
Девойко мари хубава,
Doncella, mía, bellida,
девойко мари гиздава,
кога ми трьгнеш за вода
doncella mía engalanada,
със чифт ми бели ха́ркоми, cuando salgas por agua con tus blancos calderos, ситно преметай но́гине, да гледам дор се нагледам marca tus cortos pasitos para mirar hasta hartarme на твое ситно ходене, на твое мирно гледане, че мислим да те отраднем във тази гора зелена, при тази чешма студена, под тази сенкя дебела. (Девинско ${ }^{5}$ ) tus menudos andares tus calmados mirares que raptarte he decidido en este verde soto, en esta fuente fría, so esta sombra espesa. (De la zona de Dévin)

(АРНАУДОВ, 1976:433)

У Недини слънце грее, върбо ле, върбо, върбице!

То не било ясно слънце, на ми било сама Неда: с черни очи еленови,

с дълги клепки босилкови

с бели зъби бисерови

с тънка снага самодивска. [... $]^{5}$
¡Donde está Neda, sol alumbra, salguero, salguero, salegar!

No ha sido el claro sol, sino ha sido sola Neda, con sus ojos negros de cierva, con largos párpados de albahaca, con dientes blancos perlados y talle grácil de ninfa.

\footnotetext{
46 ALATORRE, Frenk, 1989, pp. 120-121. El ejemplo es de Chistes hechos por diversos autores, p. 28.

47 En Alvar, Cantos de boda, pp. 226 (FRENK I, 1989:255). Véase además: Sebastián de Orozco, Cancionero, 1874, p. 63 (CEJADOR I, 1987: 99). "Nina de rubios cabellos" en Canc. Barbieri, núm. 103. Cantar del siglo XV (CEJADOR III, 1987: 184). Juan Vásquez, Recopilación, II, 38 (FRENK, 1989: 120).

48 Traducción de Nadia Eremíeva.
} 
(АРНАУДОВ, 1976:604)

Las fórmulas para describir la belleza de la mujer son parecidas en las dos tradiciones líricas que comparamos. En la literatura búlgara la mujer guapa brilla más que el sol, como acabamos de ver en la última poesía traducida. El mecanismo de la comparación es parecido en la poesía hispánica:

¡Ay, cuán linda que eres, Alba,

más linda que no la flor! 49

$\mathrm{Y}$ en este otro ejemplo:

Esta es blanca como el sol, que la nieve no. [...]

con quien es la nieve negra

y del almendro la flor 50 .

Un rasgo distintivo entre las dos literaturas que comparamos, dentro del tema de la belleza femenina, es que en la literatura búlgara se valoran su arte para cantar y sus aptitudes comunicativas: като дума бисер ниже ('al hablar engarza perlas'):

Не е мома като мома,

на е мома - ясно сльнце,

очите и - ясни дзвязди,

веждите и - плетен гайтан,

като оди - вятър вяе,

като седи - сльнце гряе,

като дума - бисер ниже.

[Ver http://liternet.bg/folklor/sbornici/bnpp/obredni/74.htm

Este tipo de retrato se repite en infinidad de variantes.

\section{Muestra variada de tópicos formales}

Además de los tópicos y temas que ya hemos visto que predominan en el tratamiento de la belleza femenina, conviene destacar otras fórmulas usadas con mucha frecuencia en la lírica popular búlgara. Algunas de ellas se relacionan con el ambiente y la naturaleza: поле широко ('campo abierto'), на пътя, на кръстопътя ('durante el camino, en la encrucijada'), студен кладенец ("fuente fría", "fontana fría", "frida fontana", "fonte frida").

Recuerdan a los que podemos encontrar en las cantigas de amigo o el propio Romance de Fonte Frida que recoge esta tradición (DÍAZ ROIG: 1989)

Otros completan la caracterización de los personajes. Así, la doncella es 'álamo grácil' (тънка топола) 'con talle esbelto, alto' (със снага тънка, висока), la casada, a su vez, es 'flor florida, linaje engendrado' (ивят иветила, род родила), pero ambas tienen 'andar menudo' (ситно ходеше). El mozo o el primer amor (първо либе) es 'pastor apuesto' ('de ojos negros y penetrantes': вакъл овчар), 'cordero escogido' ('con mancha negra alrededor de los ojos': вакло ягне) у cordero señalado (marcado, sagrado: ягне нишанлия).

\footnotetext{
49 Linares, Juan de, Flor de enamorados, y Timoneda, Rosa de amores, según M. Pelayo y Wolf. Es del siglo XV, originariamente mucho más antiguo (CEJADOR II, 1987:178-179).

50 Rojas Zorrilla, Francisco de, Del rey abajo (CEJADOR III, 1987:147).
} 
A continuación marcamos una coincidencia significativa entre ambas literaturas. Se trata de la fórmula "para en uno son los dos" que expresa la idoneidad de los amantes y que tiene su parangón en la frecuente expresión búlgara: “... са си ликаприлика". Los ejemplos son numerosos en ambas literaturas ${ }^{51}$.

Para en uno son los dos:

vivan, y guárdelos Dios ${ }^{52}$.

Menga y Antón

para en uno son ${ }^{53}$.

Otras fórmulas de repetición que merecen ser mencionadas son las que introducen diálogos. Las fórmulas más comunes de este tipo son: вели и говори; вели говори ('y habla y dice') para expresar decisión; тихо говори ('habla en voz baja') para expresar humildad у люто заклина ('amargo maldice') para manifestar indignación. Las completan otras que hablan de sus acciones y actitudes cotidianas, codificadas simbólicamente a través de expresiones formales recurrentes como: отдолу идеше ('de abajo venía', 'subía la cuesta'), бело платно белат ('blanca tela blanquean'), руйно вино пият ('vino claro beben').

Entre los recursos formales que hemos venido observando, se da también la repetición fónica de palabras homónimas (homófonas y homógrafas), como en el siguiente ejemplo.

¡Ay, que no hay amor sin ay!

¡ay que su ay tanto me duele,

que muero por ver si hay

algún ay que mi ay encele

que el dolor no lo revele! ${ }^{54}$

La interjección ay tiene un uso muy divulgado, puesto que existe también el baile del Ay ay ay ${ }^{55}$.

Querríamos resaltar otro recurso más de repetición fónica. Se trata del que observamos en la siguiente seguidilla. Lo añadido al tercer verso se llamó eco.

Como somos niñas

somos traviesas

y por eso nos guardan (jardan!)

todas las dueñas.
No se halla dueño

deste cautivo

sino una fregata

(gata)

que dijo mío. $[\ldots]^{56}$

El uso de onomatopeyas es otro recurso de repetición fónica que aporta ritmo y musicalidad y que es ampliamente usado en todas las tradiciones populares europeas.

\footnotetext{
51 Véase, por ejemplo, la accesible colección en LiterNet de cantos populares: БОЯДЖИЕВА, С. (2005) „Т. IV Народни балади" в Българска народна поезия и проза в седем тома, LiterNet, Варна. < http://liternet.bg/folklor/sbornici/bnpp/baladi/content.htm>

52 FRENK, 1989: 556. CЕЈADOR III, 1987: 207-208. АРНАУДОВ (1976). Esta poesía, además, es un buen ejemplo de los cánones de la belleza masculina y femenina.

53 Correas, Vocab., p. 460. En CEJADOR I (1987).

54 Canc. Costantina, núm. 145 (CEJADOR III, 1987: 86).

55 Villancicos, Real Capilla, 1696; el baile del Ay ay ay y Villancicos, Sevilla, 1720 (CEJADOR III, 1987:90-91).

56 El ejemplo es de comienzos del XVII, Conzalo Correas, Arte grande, p. 270 (CEJADOR II, 1987:40-42).
} 


\section{Conclusiones}

En este estudio nos hemos centrado en algunas de las semejanzas entre los tópicos semánticos y formales de la tradición lírica hispánica y la lírica popular búlgara. De la lírica popular búlgara, hemos analizado fórmulas y motivos recurrentes en los cantares de amor, resaltando las diferencias y similitudes con el Corpus de la antigua lírica popular hispánica. Hemos destacado algunos paralelos -tanto en el nivel semántico-temático, como en varios aspectos formales- que están presentes en toda la tradición lírica europea. Especial interés nos han merecido los temas recurrentes relacionados con las festividades que marcan el inicio del año agrícola y del verano y simbolizan el despertar de la vida natural, la resurrección y la celebración del amor: las Mayas, el día de San Juan y el día de San Jorge (en el caso del folclore búlgaro). Hemos reseñado la influencia que ejercen los ideales corteses en la tradición centroeuropea y occidental, al introducir motivos como "las justas de amor", el "mal de amores" y el "morir de amor" o el clásico ideal de la rubia belleza femenina.

Hemos seleccionado los tópicos semánticos y formales, además de algunos epítetos constantes, que podríamos considerar representativos en el de tratamiento de la belleza femenina en ambas literaturas. La traducción que hemos hecho de algunas canciones populares búlgaras y de muchas fórmulas y epítetos recurrentes es solo una de nuestras aportaciones al tema investigado.

\section{Referencias bibliográficas}

1913-2002: Сборник за народни умотворения (СбНУ), БАН, София.

ARMISTEAD, S. G. (1996): "Los estudios de la poesía improvisada antes de la décima", Prólogo a TRAPERO, M., El libro de la décima. La poesía improvisada en el mundo hispánico, Unelco, Universidad de las Palmas de Gran Canaria, Cabildo Insular de Gran Canaria , pp. 3-34.

BAJTIN, M. (1989): "Las formas del tiempo y del cronotopo en la novela. Ensayos sobre Poética Histórica", en Teoría y estética de la novela, Taurus, Madrid.

BAROJA, C. (1985): La estación de amor, Taurus, Madrid.

CEJADOR Y FRAUCA, J. (1987): La verdadera poesía castellana. Floresta de la antigua lirica popular. Recogida y estudiada por D. Julio Cejador y Franca, Tomos I, II y III, Arco Libros, Madrid.

DÍAZ GONZÁLEZ, J. (1981): "La mañana de San Juan en el Romancero", Revista de folklore, 6/1 ${ }^{\mathrm{a}}$, pp. 11-13<http://www.funjdiaz.net/folklore/07ficha.cfm?id=60>

DÍAZ ROIG, M, ed. (1989): El Romancero viejo, Cátedra - Letras Hispánicas, nº 52. 13ª ed., Madrid.

FRENK ALATORRE, M. (1990: $2^{\mathrm{a}}$ ed. de 1987): Corpus de la antigua lirica popular hispánica (siglos XV a XVIII), Castalia, Madrid.

FRENK ALATORRE, M. (ed.) (1989): Lírica española de tipo popular, Cátedra, Madrid.

LÁLEVA, T. D. (2007): Diccionario bilingüe de términos literarios. Búlgaro-Español, Español-Búlgaro, Gram Ediciones, Madrid.

MENÉNDEZ PELAYO, Antología de poetas líricos castellanos. La poesía en la Edad Media, t. 1. (Edición digital de Enrique Sánchez Reyes a partir de Edición nacional de las obras completas de Menéndez Pelayo. Vol. 17, Madrid, CSIC, 1944) < http://www.cervantesvirtual.com/servlet/SirveObras/13504842012573728522202/029120.pdf $>$ 
MENÉNDEZ PIDAL, R. (1920): “La primitiva poesía lírica española”, en Estudios literarios, Atenea, Madrid, pp. 340-341.

АНГЕЛИЕВА, Ф. (1980): “Цветовете в гръцките народни песни”, Балкански културни взаимоотношения, София, с. 51-55.

АРНАУДОВ, М. (1976-1977): Вековно наследство. Българско народно поетическо творчество, I-II, Наука и изкуство, София.

АРНАУДОВ, М. (2005): Български народни песни, I, Лирика, LiterNet, Варна. < $\mathrm{http} / / /$ liternet.bg/folklor/sbornici/lirika/75.htm>

БОЯДЖИЕВА, С. (2005): „Том IV: Народни балади” в Българска народна поезия и проза седем тома, LiterNet, Варна. $<$ http://liternet.bg/folklor/sbornici/bnpp/baladi/content.htm $>$

БУРИН, И,. ПАНАЙОТОВА, Ф. (2005): Сокол иде, гълъбица води. Народна любовна лирика, LiterNet, Варна <http://liternet.bg/folklor/sbornici/sokol/59.htm>

ВАНГЕЛОВ, А. (1986): Семантичките фигури в македонската народна лирика, Скопје.

ВЕЛЕВ , Г. (2000): Българският народен календар. Основи и същност, I, ИК Тангра ТанНакРа, София.

ВЕСЕЛОВСКИЙ, А. (1989): Историческая поэтика, Москва.

ГЕОРГИЕВА, С. (1986): Фолклор на с. Черково, Бургаски окръг, Дипломна работа Архив по фолклор на ШУ, Шумен.

ИВАНОВА, Р., ЖИВКОВ, Т. (съст.) (2004): Лудо младо взема мома змейовица за невеста. Българска народна поезия и проза в седем тома, Т. II. Обредни песни. $<$ http://liternet.bg/folklor/sbornici/bnpp/obredni/74.htm>

ИВАНОВА, Р., ЖИВКОВ, Т. (съст.) (2004): Руса мома ще наказва лудо младо. Българска народна поезия и проза в седем тома. T. II. Обредни песни. LiterNet, Варна. $<$ http://liternet.bg/folklor/sbornici/bnpp/obredni/99.htm>

КАЛОЯНОВ, А. (съст., ком. и бел.) (2002): Русин юнак замерва със стрела Руса мома, Liternet, Варна. <http://liternet.bg/publish/akaloianov/iunak/32.htm>

КОЛЕВА, В. (2002): Естетика и ритуал, Литернет, Варна $<$ http://liternet.bg/publish/vkoleva/estetika/content.htm $>$

КОЛЕВА, Т. (1981): Гергьовден у южните славяни, БАН, София.

МАРИНОВ, Д. (1994): Народна вяра и религиозни народни обичаи, БАН (второ фототипно издание: ВАСИЛЕВА, М. съст. и ред.), София.

МИЛАДИНОВИ, Д. и К. (2003): Български народни песни, ІІ т., Захарий Стоянов, София.

ОСИНИН, Д., БУРИН, Ив. (съст.) (2006): Ой орехо, ой мой братко, Любовни песни, т. VI. Българско народно творчество в дванадесет тома, Liternet, Варна. $<$ http://liternet.bg/folklor/sbornici/bnt/6/638.htm>

ТЕОДОРОВ, Е. (1972): Древнотракийското наследство в българския фолклор, Наука и изкуство, София.

УМЛЕНСКИ, И. (1950): Село Багренцุи, Кюстендилско. Историко-поселищно и стопанско-битово изследване, АЕИМ № 1012 - БАН, София.

ЦОНЕВ, Б. (съст.) (2006): Змей Никола отвлича Руса мома. Родна китка: Отбор народни песни, Liternet, Варна <http://liternet.bg/folklor/sbornici/rodna_kitka/17.htm>

ШАПКАРЕВ, К. (съст.) (2008): Митро, мома Митро. Сборник от български народни умотворения, Т. 1. Песни. Liternet, Варна. <http://liternet.bg/folklor/sbornici/shapkarev_1/1135.htm> 